\title{
Modeling of repairable multi-state systems with time-varying failure and repair rates using equivalent systems dynamics models
}

\author{
Modelo para un sistema multi estado reparable con tasas de reparación y fallas \\ variables en el tiempo utilizando modelos de dinámica de sistemas equivalente
}

\author{
M. Narváez-Velasco iD ; J. C. Osorio-Gómez iD
}

\begin{abstract}
This paper treats with the reliability assessment of a Repairable Multi-State System (RMSS) by means of a Nonhomogeneous Continuous-Time Markov Chain (NH-CTMC). A RMSS run on different operating conditions that may be considered acceptable or unacceptable according to a defined demand level. In these cases, the commonly used technique is Homogeneous Continuous-Time Markov Chain (H-CTMC), because its solution is mathematically tractable. However, the $\mathrm{H}$ CMTC involve that the time between state transitions is exponentially distributed, and the failure and repair rates are constants. It is certainly not true if the system components age with the operation or if the repair activities depend on the instant of time when the failure occurred. In these cases, the failure and repair rates are time-varying and the NH-CTMC is needed to be considered. Nevertheless, for these models the analytical solution may not exist, and the use of other techniques is required. This paper proposes the use of an Equivalent Systems Dynamics Model (ESDM) to model a NH-CTMC. An ESDM represent the Markov Model (MM) by means of the Systems Dynamics (SD). As an example, an RMSS with three components is developed. This example serves to identify the advantages and disadvantages of a ESDM to make model a RMSS and evaluate some reliability measures. Finally, it is found that the dynamic model allows a suitable solution for the system, with less computational effort.
\end{abstract}

Index Terms - Failure analysis, Reliability, Systems Dynamics, Markov Chain, failure functions.

Este manuscrito fue enviado el 19 de febrero de 2020 y aceptado el 05 de septiembre de 2020.

Trabajo de investigación derivado del trabajo de grado de la autora Narváez bajo la dirección del autor Osorio como requisito para el grado de Ingeniería Industrial.

M. Narváez-Velasco, Ingeniera Industrial egresada de la Universidad del Valle, Magister en Finanzas de la Universidad Icesi, Santiago de Cali, Colombia. (e-mail: marce.narvaezve@ gmail.com).

J. C. Osorio-Gómez, Ingeniero Industrial, Doctor en Ingeniería Industrial de la Universidad del Valle, Santiago de Cali, Colombia, y profesor titular de la Escuela de Ingeniería Industrial (e-mail: juan.osorio@correounivalle.edu.co).
Resumen-Este artículo aborda la evaluación de la confiabilidad de un sistema multi estado reparable (SMER) por medio de una cadena de Markov de tiempo continuo no homogénea (CMTC-NH). Un SMER se ejecuta en diferentes condiciones de funcionamiento que pueden considerarse aceptables o inaceptables según un nivel de demanda definido. En estos casos, la técnica comúnmente utilizada es la Cadena de Markov de Tiempo Continuo Homogénea (CMTC-H), ya que su solución es matemáticamente manejable. Sin embargo, el CMTC-H implica que el tiempo entre las transiciones de estado se distribuye exponencialmente, $y$ las tasas de falla $y$ reparación son constantes. Ciertamente no es cierto si los componentes del sistema envejecen con la operación o si las actividades de reparación dependen del instante en que se produjo el error. En estos casos, las tasas de falla $y$ reparación varían en el tiempo y se necesita que las CMTC-NH sean consideradas. Sin embargo, para estos modelos la solución analítica puede no existir y se requiere el uso de otras técnicas. Este documento propone el uso de un modelo de dinámica de sistemas equivalente (MEDS) para modelar un CMTC-NH. Un MEDS representa el Modelo Markov (MM) por medio de la Dinámica de Sistemas (SD). Se desarrolla un ejemplo de SMER con tres componentes. Este ejemplo sirve para identificar las ventajas y desventajas de un MEDS para hacer modelo un SMER y evaluar algunas medidas de confiabilidad. Finalmente se encuentra que el modelo dinámico permite una solución adecuada para el sistema, con menos esfuerzo computacional.

Palabras claves - Análisis de falla, Confiabilidad, Dinámica de sistemas, cadenas de markov, funciones de falla 


\section{INTRODUCTION}

The increasing complexity of the systems and performance guarantee has given greater importance to reliability analysis. The reliability analysis aim is to estimate the probability of system failure based on the characteristics and relationships between system components and others interest parameters [1].

Distefano [2] identifies two basic approaches to do this task: The experimental measurement and the construction of a system model. The experimental measurement involves to collect empirical data of time to failure and the reliability index is the percentage of systems that have not failed until a given instant of time. However, this test is complicated and expensive in most of the real problems [3].

Respect to the construction of a system model, as in any other discipline, a model is a mathematical or graphical representation of the system features. From this abstract model is possible to estimate different measures and do others quantitative analysis [4].

According to Kuo y Zuo [5], although different models for reliability analysis exist, its application can have serious limitations. On the one hand, the real systems depend on the dynamics of its components and the model should be able to incorporate interdependencies between them. On the other hand, the time and resources to solve the model should be adequate and efficient in practice.

In order to overcome the previous limitations, this paper presents a methodology to model complex systems, based on the representing of its operating modes of operation and two different modeling techniques.

\section{REPAIRABLE MULTI-STATE SYSTEM (RMSS)}

The system components and how these are organized have a direct effect on functionality [6]. According to Levitin and Lisnianski [7], this is reflected in the system ability to perform their tasks at different performance levels. When system doesn't respond to a defined performance indicator is incapable of to perform its function. This means that the system has failed.

For Xie et al [8], the system has opportunity to operate under different conditions while this is degraded and repaired. This process generates a set of operating states, hence that the systems with this quality are known in the literature as MultiState Systems (MSS). Soro et al [9] explain that this feature stems from effects of component deterioration and of changes in environmental conditions that can lead to partial failures and repairs. Formally, according to Liu and Kapur [10], if $y$ is a performance measure, then MSS operating conditions can be classified according to $\mathcal{t}_{\mathrm{i}}$ as:

$$
v_{i}=\left\{\begin{array}{cc}
0 & \text { Si } y_{0} \leq y \leq y_{1} \\
\vdots & \vdots \\
i-1 & \text { Si } y_{i-1} \leq y \leq y_{i} \\
\vdots & \vdots \\
K-1 & y \geq y_{K}
\end{array}\right.
$$

Each $v_{i}$ is a different state and $y_{i}, i=1,2, \ldots, K$ are threshold levels from which system operates in different ways. Usually, a performance discrete value $g_{v_{i}}$ can be assigned a $v_{i}$. It can be the average of $y_{i}$ and $y_{i-1}$ or some characteristic value. Therefore, the MSS state in an instant of time $t$ can be represented by a random variable $X(t)$ that takes values on $¥=\left\{0 \ldots, v_{i}, \ldots, K-1\right\}$. In addition, $¥$ can be divided into two subsets $\mathfrak{x}^{A}$ and $\mathfrak{x}^{I}$, which contain the acceptable and unacceptable (failure) operating states respectively [11].

The membership of $v_{i}$ to $x^{A}$ or $x^{I}$ is given by the acceptability function $F(X(t), w)$. It functions takes nonnegative values if and only if associated performance level is acceptable. According to Soro et al [9] this is summarized on the following criteria:

$$
\begin{aligned}
& \text { i. } \quad X(t) \in \mathfrak{X}^{A} \text { if } F(X(t), w) \geq 0 \text {, and } \\
& \text { ii. } \quad X(t) \in \mathbb{X}^{I} \text { if } F(X(t), w)<0 .
\end{aligned}
$$

Generally, the acceptability function is defined as $F(X(t), w)=g_{x(t)}-w$, such that system makes a transition or enters at fault condition at in time $t$ when it isn't capable to supply a determined demand level.

A MSS is repairable (RMSS) if can also make transitions from a given state to a state with higher performance. In other words, a repair occurs when the system changes from a $v_{i}$ to $v_{j}$, such that $g_{v_{i}}<g_{v_{j}}[12]$.

Since $X(t)$ is a random variable, the RMSS behavior over time can be represented by a stochastic process. In reliability theory, the most widely used processes are the Markov Model (MM) which are well known and studied. Particularly, the Continuous-Time Markov Chains (CTMC) are the most popular because easily understood and relative mathematical tractability [13].

\section{Continuous-Time Markov Chain (CTMC).}

According to Ross [14], a stochastic process $\{x(t), t \geq 0\}$ with continuous time and state space $¥=\left\{0 \ldots, v_{\mathrm{i}^{x} \ldots,} \mathrm{K}-1\right\}$ is a MM if it satisfies the Markov property which is shown in (1):

$\operatorname{Pr}\left(X(t)=v_{j} \mid X(\tau)=v_{i}, X(u)=x(u), 0 \leq u<\tau\right)=\operatorname{Pr}\left(X(t)=v_{j} \mid X(\tau)=i\right)$

In words, this property indicates that the conditional probability at in future instant of time $X(t)=v_{j}$ given the present state $X(\tau)=v_{i}$ with $v_{i}, v_{j} \in \underset{x}{x}$ and past states $X(u)=x(u), 0 \leq u<\tau$, depends only on the present state. That is to say, the system future development is independent of the past events [15]. 


\section{A. Definition of a CTMC}

Rausand and Hoyland [16] note that a CTMC can be completely described by defining:

- The state space $¥$, and

- The matrix of transition rates $\mathbb{A}(t)$. Each component $a_{i j}(t)$ of this matrix is the hazard function for the transition from $v_{i}$ to $v_{j}\left(v_{i} \rightarrow v_{j}\right)$.

According to Bukowski [17] a CTMC is solved by finding the states probability distribution $\mathbf{p}(t)=\left[p_{v_{0}}(t), \ldots p_{v_{i}}(t), \ldots, p_{v_{K-1}}(t)\right] \quad$ where $p_{v_{i}}(t)=\operatorname{Pr}\left\{X(t)=v_{i}\right\}$. This is equivalent to solving system of Ordinary Differential Equations (ODE) defined by:

$$
\begin{aligned}
& \frac{d p(t)}{d t}=\mathbf{p}(t) \cdot A(t) \\
& \sum_{j=0}^{x} p_{v_{i}}(t)=1
\end{aligned}
$$

(4)

$$
p_{i j}(\tau, t)=\operatorname{Pr}\left(X(t)=v_{j} \mid X(\tau)=i\right) \text { was previously defined }
$$
and it is a function on $(\tau, t)$ and not only on $t-\tau$. This is the most general case and it is called Nonhomogeneous CTMC (NH-CTMC). However, when $p_{\mathrm{i} j}(\tau, t)$ depends only on $t-\tau$, the $\mathrm{MM}$ is a Homogeneous CTMC (H-CTMC) and all transition rates $a_{\mathrm{ij}}(t)$ are constant functions in time [18].

The H-CTMC is the most widely used model in practice because its solution is easier than nonhomogeneous solution. In fact, the H-CTMC solution obtained from the system of ODE defined by (3) and (4) has the form $\mathbf{p}(t)=\mathbf{p}\left(t_{0}\right) e^{\mathbb{A}_{(}\left(t-t_{0}\right)}$ where $e^{\text {Qit }}$ is the exponential matrix $e^{Q_{\text {at }}}=\sum_{k=0}^{\mathrm{e}} \mathbb{A}^{k} t^{k} / k !$ and $\mathbf{p}\left(t_{0}\right)$ is the initial probability distribution, such that if $\{X(t), t \geq 0\}$ was in the state $v_{i}$ in $t_{0}$, then $p_{v_{i}}\left(t_{0}\right)=1$ and $p_{v_{j}}\left(t_{0}\right)=0$ for all $v_{j} \neq v_{i}[17]$.

However, the above result is not valid for a CTMC-NH in which the transition matrix $\mathbb{A}(t)$ has components that are functions of overall process time, and generally a closed form solution for the set of ODEs isn't possible to define [19]. For these cases, different techniques have been proposed. Some of these propose to convert the nonhomogeneous process in a homogeneous model using uniformization or time discretization ([17], [11], [19]). Unfortunately, same mistakes of the homogeneous case can be obtained if used parameters aren't adequate [20].

De Souza e Silva and Gai [21] indicate that others types of techniques such as the numerical approximation methods don't present the above difficulties. In particular the Runge-Kutta (RK) methods have proved to be the most appropriate numerical techniques for dealing with nonhomogeneous MM. This method consists basically of an algorithm with iterative calculations in each time increment of size $h$. Most general purpose mathematical software commercially available as
Maple $^{\circledR}$ y Matlab ${ }^{\circledR}$ contain codes for solving systems of ODE through various numerical methods. However, the set of equations must be made explicitly in these tools, which becomes complex when $¥$ has more than 10 or 15 elements.

Although accuracy is affected by integration errors, the RK methods are characterized by flexibility to deal with almost any type of ODE and because satisfactory estimates are obtained while $h$ is reduced and the integration order is increased [22].

\section{B. Graphical representation of a CTMC}

According to graph theory, every square matrix has an associated graph whose representation contains vertices and directed arrows. This matrix corresponds to $\mathbb{A}(t)$ in the MM, and its representation is known as Transition Diagram (DT) [23]. When a MM is studied its analysis usually begins by building a DT where:

- Each state $v_{i}$ is represented by a node called ${ }^{\mathrm{m}} v_{i}{ }^{\mathrm{I}}$. Therefore, there are $K$ nodes.

- Each transition $v_{i} \rightarrow v_{j}$ is represented by an directed arrow from the node " $v_{i}{ }^{\mathrm{I}}$ to the node " $v_{j}{ }^{\mathrm{m}}$. It's labeled with the associated rate $a_{\mathrm{ij}}(t)$.

- Each transition $v_{i} \rightarrow v_{i}$ can be represented by a directed arc from the node $v_{\mathrm{i}}$ to itself. However, the arc can be obviated if the others transitions have already been completely determined using (2).

\section{CTMC for a RMSS}

In general terms, when a $\mathrm{MM}$ is used to assess system reliability, the set of states contains the system operating modes and the hazard functions correspond to the failure and repair rates of system components [24].

This is because if the RMSS has $n$ components, each state $v_{\mathrm{i}}$ is associated a vector $\left(v_{1 \mathrm{i}}, v_{2 \mathrm{i}}, \ldots, v_{\mathrm{ki}}, \ldots, v_{n i}\right)$ where $v_{k \mathrm{i}}$ is the condition of component $k$ when system operates in $v_{i}$. If the components are binary then $v_{k i} \in\{0,1\}$, such that $v_{k i}=0$ if the component is operating and $v_{k i}=1$ if the component has failed [25]. Thus, for a transition $v_{i} \rightarrow v_{j}$ :

- $a_{\mathrm{ij}}(t)=\lambda_{m}(t)$ if $v_{k i}=v_{k j} \forall k \neq m, v_{m i}=0$ and $v_{m j}=1$.

- $a_{\mathrm{ij}}(t)=\mu_{m}(t)$ if $v_{k i}=v_{k j} \forall k \neq m, v_{m i}=1$ and $v_{m j}=0$.

Where $\lambda_{m}(t)$ and $\mu_{m}(t)$ are the failure and repair rates of the component $m$ respectively.

According to Liu and Kapur [10], the failure rate is constant if the considered system doesn't suffer degradation due to age or to any special conditions that may increase its tendency toward failure. In this case, the failure occurs as a random event without any dependence of the overall operating time. In the same way, if the repair rate is constant then the model 
ignores possible effects of the maintenance resources availability and repair activities efficiency [26].

Despite these considerations, in practice known and constant hazard functions are assumed and these are estimated under stationary assumption in order to take advantage of the mathematical clarity and simplicity in the homogeneous MM [13]. Nevertheless, the problem is that in reality the state and the time amount that system remains here not only depend on the current condition, but also how long the system has been in use or operation. These cases require the use of NH-TCMC where the failure and repair rates are Time-varying functions [27].

But as noted in section 3.1, the numerical solution of $\mathrm{NH}$ CTMC has great limitations and only a small number of applications take the risk of to work with these models. Platis [26], Liu and Kapur [28], Ermolin [13], Liu and Kapur [23], Lisnianski et al [29] and Liu and Huang [27] present some well-formulated works dealing with nonhomogeneous MM to assess reliability.

However, Narvaez and Osorio [31] developed an approach to solve NH-CTMC that is called Equivalent System Dynamics Model (ESDM). This model is based on the mathematical equivalence between the MM and Systems Dynamics Models (MDS). Although Systems Dynamics (DS) has been usually related to the modeling in the humanities, economic and biological disciplines, it is based on the theory of nonlinear dynamical systems which is typically developed in mathematics, physics and engineering [30].

Narvaez and Osorio [31] established a procedure to construct a SDM with mathematical formulation equivalent to system of ODE in (3) and (4), so a CTMC can be represented by means of DS language and the DS computational simulation tools can be used to resolve model.

\section{EQUIVALENT SySTEM DYNAMICS MODEL (ESDM)}

A ESDM is a Forrester Diagram (FD) for a TD. A DF is a system graphical representation where each system element $q_{j}$ is represented by a particular type of variable depending on its characteristics [32]. These variables are summarized in Table I.

TABLE I

DF'S VARIABLES

\begin{tabular}{cccc}
\hline Variable & \multicolumn{2}{c}{ Symbol } & \multicolumn{1}{c}{ Description } \\
\hline Level & $Y(t)$ & $Y(t)_{j}$ & Value of $q_{j}$. Dynamic quantity. \\
Flow & $r_{j i}$ & $c_{r_{j i}(t)}$ & $\begin{array}{l}\text { Element that controls the transfer rate } \\
\text { from } q_{j} \text { to } q_{i} \text {. Dynamic quantity. }\end{array}$ \\
Fuxiliary & $c_{j(t)}(t)$ & $c_{j i}(t)$ & $\begin{array}{l}\text { Element related to } r_{i j}(t) \text {. Exogenous or } \\
\text { intermediate quantity. }\end{array}$ \\
Information \\
connector
\end{tabular}

Source. Based on Burns [33].
According to Narvaez and Osorio [31], the conversion from a TD to a FD involves:

- Create a level variable $Y(t)_{j}$ called $^{\mathrm{I}} t^{\mathrm{N}}$.

- Create a level variable $Y(t)_{j}$ called ${ }^{\mathrm{I}} \operatorname{Pr}\left\{X(t)=v_{j}\right\}^{\mathrm{I}}$ for each node $\nu_{j}$ in TD.

- Draw a flow connector from the level variable called ${ }^{\mathrm{I}} \operatorname{Pr}\left\{X(t)=v_{j}\right\}^{\mathrm{I}}$ to ${ }^{\mathrm{I}} \operatorname{Pr}\left\{X(t)=v_{i}\right\}^{\mathrm{I}}$ for each directed arrow $v_{j} \rightarrow v_{i}$ and call the corresponding flow variable ${ }^{\mathrm{n}} r_{\mathrm{f}}(t)^{\mathrm{I}}$.

- Create a auxiliary variable $c_{j}(t)$ for each $a_{j}(t)$ in TD. It is labeled ${ }^{\mathrm{m}} a_{j}(t)^{\mathrm{I}}$.

- Draw a information connector from "Pr $\{X(t)=j\}^{\mathrm{II}}$

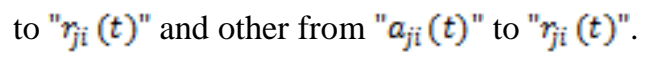

\section{A. Mathematical formulation of a EDSM}

The value of each variable is given by the following mathematical relationships.

- $\quad$ For each level variable "Pr $\{X(t)=j\}^{1}$ :

$$
\operatorname{Pr}\left\{X(t)=v_{j}\right\}=\operatorname{INTEG}\left\{\left(\sum_{\substack{j=0 \\ i \neq j}}^{y} r_{i j}(t)-\sum_{\substack{j=0 \\ i \neq j}}^{y} r_{j i}(t)\right), p_{v_{j}}\left(t_{0}\right)\right\}
$$

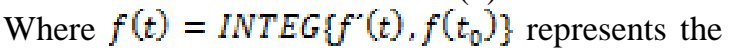
integral of $f^{2}(t)$ with initial value $f\left(t_{0}\right)$.

- $\quad$ For each flow variable " $r_{\mathrm{T}}(t)^{\mathrm{m}}$ :

$$
r_{j}(t)=a_{j}(t) \operatorname{Pr}\left\{X(t)=v_{j}\right\}
$$

- For each auxiliary variable ${ }^{\mathrm{m}} a_{j \mathrm{j}}(t)^{\mathrm{m}}$ to write the corresponding transition rate.

- For the level variable " $t$ " :

$$
t=\operatorname{INTEG}\left\{1_{s} t_{0}\right\}
$$

\section{B. Simulation of a EDSM}

The CTMC solution corresponds to the simulation of EDSM. This can be done through any of the available DS software such as Stella, Powersim, Optisim and Vensim [34]. In this paper Vensim Professional 32 software version 5.3 is used.

These software get results from numerical integration of implicit differential equations system in the model. In particular, Vensim Professional 32 version 5.3 allows to choose different RK numerical approximation methods, such as the Euler method, second order RK (RK-2) and fourth-order RK (RK-4). This also allows to select $h$ as fixed value or as value that is automatically adjusted to ensure relative and absolute errors less than 0.0001 [35]. 
Finally, the simulation interval should also be assigned. For an ESDM, initial time instant corresponding to $t_{0}$ and the final time corresponds to analysis period of stochastic process.

\section{APPLiCATION CASE: AIR-CONDITIONING SYSTEM}

Recognizing the homogeneous MM limitations and the ESDM benefits, this paper illustrates how the SD approach is used to model a NH-CTMCR of a RMSS and estimate some reliability measures. A modified model based on Lisnianski et al [29] is proposed and it is described below.

There is a climate control system that consists of two main air conditioners and one reserved air conditioner and its operation has following assumptions:

- Initially, the two main air conditioners are operating and the reserved air condicioner is a standby equipment. The reserved air conditioner comes online only if one of the main equipment fails.

- The reserve air conditioner does not fail until it has begun operations.

- The times to failure of all air conditioner follow a Weibull distribution. So the rates for main equipment is $\lambda(t)=1.2 t^{0.2}$, while the reserved equipment have rate equal to $\lambda(t)_{Y}=1.5 t^{0.5}$.

- The times to repair follow a Log-logistic distribution and it is same for all air conditioner. This is, $\mu(t)=\mu(t)_{r}=2 t /\left(1+t^{2}\right)$.

- The air conditioners operation and fail are independent of the others equipment.

- An automatic system activates the reserved air conditioner right in the moment when one of the main equipment fails.

- There is only one repair facility such that only one equipment can be repaired at once and the repair is performed first for the equipment that first failed.

The Table II describes the RMSS states where A and B are the main air conditioners and $\mathrm{C}$ is reserved air conditioner. Each equipment is a binary system, but $\mathrm{C}$ can also be on hold (it isn't online or failed but it is availability). This is indicated by the sign "-".

TABLE II:

AIR-CONDITIONING System STATES

\begin{tabular}{ccccc}
\hline \hline $\begin{array}{c}\text { State of } \\
\text { RMSS }\end{array}$ & $\begin{array}{c}\text { State } \\
\text { of A } \\
v_{\hat{i}}\end{array}$ & $\begin{array}{c}\text { State } \\
\text { of B } \\
v_{A i}\end{array}$ & $\begin{array}{c}\text { State } \\
\text { of C } \\
v_{C i}\end{array}$ & $\begin{array}{c}\text { Performance } \\
\text { Level } \\
g_{\nabla_{\mathrm{i}}}\end{array}$ \\
\hline 5 & 0 & 0 & - & 4 \\
4 & 0 & 1 & 0 & 3 \\
3 & 1 & 1 & 0 & 1 \\
2 & 0 & 1 & 1 & 2 \\
1 & 0 & 0 & 1 & 4 \\
0 & 1 & 1 & 1 & 0 \\
\hline \hline
\end{tabular}

Source: Authors.

Thus, the air-conditioning system can be represented by a CTMC $\{X(t), t \geq 0\}$ with states space $¥=\{0,1,2,3,4,5\}$ and the TD that is showed in the Fig. 1, where transition rates between each pair of states are also assigned.

For this example, the acceptability function is defined as $F(X(t), w)=g_{X}(t)-w$ with $w=3$. Thus, $x^{I}=\{0,2,3\}$ and $x^{A}=\{1,4,5\}$.

Following the procedure described in the section 4, the TD for the air-conditioning system EDSM is presented in the Fig. 2.

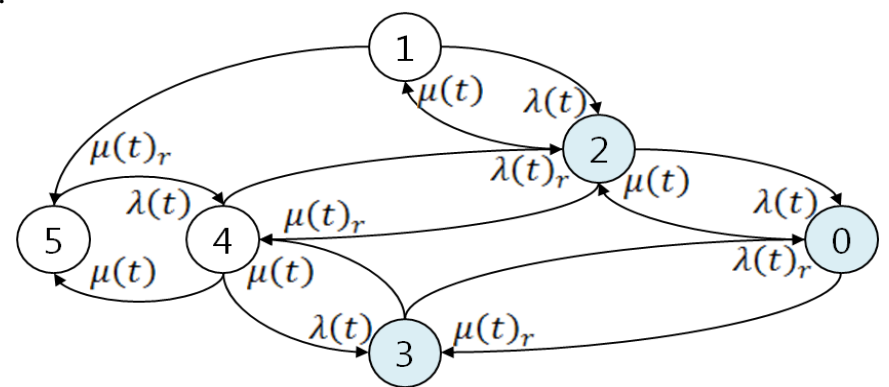

Fig 1: TD of an Air-conditioning system.

Source: Authors.

Since initially both main air conditioners are online and the reserved air conditioner has not begun operation, then $\mathbf{p}(0)=[0,0,0,0,0,1]$. Thus, (5) yields:

$$
\begin{aligned}
& \operatorname{Pr}\{X(t)=5\}=\operatorname{INTEG}\left\{\left(\sum_{\substack{j=0 \\
i \neq 5}} r_{i 5}(t)-\sum_{\substack{j=0 \\
i \neq 5}} r_{5 i}(t)\right), 1\right\} \\
& \operatorname{Pr}\left\{X(t)=v_{j}\right\}=\operatorname{INTEG}\left\{\left(\sum_{\substack{j=0 \\
i \neq j}} r_{i j}(t)-\sum_{\substack{j=0 \\
i \neq j}} r_{j i}(t)\right), 0\right\} \quad \forall \quad v_{j} \neq 5
\end{aligned}
$$

Flow functions are defined by (6) where $a_{j 1}(t)$ correspond to failure and repair rates, while $t$ is defined from (7) with $t_{0}=0$.

The simulation is performed in Vensim Professional 32 version 5.3 with initial time instant 0 , final time 10 , $h=0.0078125$ and RK-4 method with automatically adjusted integration step. Thus, the values of level variables at a time $t$ are estimates for RMSS probability distribution $\mathbf{p}(t)$.

A. Results: Air-conditioning system performance measures

With previous estimates is possible to calculate different performance measures such as availability, reliability, expected performance and mean time to failure as described below.

$$
\text { Availability } \boldsymbol{A}(\boldsymbol{t}) \text { and stationary availability } \boldsymbol{A}
$$

The following variables must be created:

- $\quad$ A auxiliary variable called ${ }^{\mathrm{m}} A(t)^{\mathrm{m}}$

- Information connectors from level variables ${ }^{\mathrm{I}} \operatorname{Pr}\left\{X(t)=v_{j}\right\}^{\mathrm{I}}$ with $j \in \mathfrak{X}^{A}$ to ${ }^{\mathrm{m}} A(t)^{\mathrm{m}}$

And the following equation must be assigned: $A(t)=\sum_{j \in x^{A}} \operatorname{Pr}\left[X(t)=v_{j}\right\}$

The stationary availability $A$ is the limit at infinity of the function (8). So if the CTMC is regular (i.e. $\lim _{t \rightarrow \infty} \mathbf{p}(t)$ 
exist), $A$ can be approximated as the value that $A(t)$ achieves at the end of simulation time.

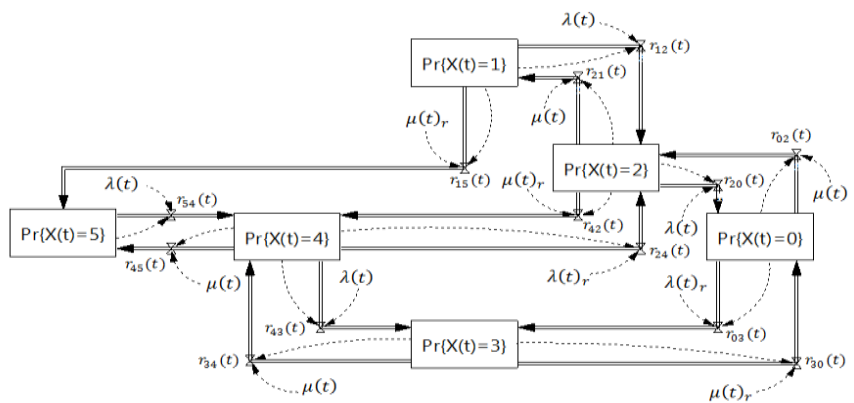

Fig 2: EDSM for the TD in the Figure 1.

Source: Authors.

\section{Expected Performance $\boldsymbol{R} \boldsymbol{E}(\boldsymbol{t})$}

$K+1$ auxiliary variables are created, one is called " $R E(t)^{\mathrm{m}}$ and the others are called " $g_{v_{j}}$ ". Then information connectors are created from all level variables ${ }^{n} \operatorname{Pr}\left\{X(t)=v_{j}\right\}^{\mathrm{I}}$ and from all the auxiliary variables " $g_{v_{j}}{ }^{n}$ to " $R E(t)^{\mathrm{m}}$, and the following equation is assigned

$$
R E(t)=\sum_{j=0}^{r} g_{w_{j}} \operatorname{Pr}\left\{X(t)=v_{j}\right\}
$$

\section{Reliability $\boldsymbol{R}(\boldsymbol{t})$}

In order to evaluate RMSS reliability, is necessary to make $\mu(t)=\mu(t)_{Y}=0$. In Vensim Professional 32 version 5.3 this can be easily done by saving a new scenario of the EDSM with repair rates equal to 0 . In this scenario ${ }^{\mathrm{m}} A(t)^{\mathrm{m}}={ }^{\mathrm{m}} R(t)^{\mathrm{I}}$.

\section{Mean Time To Failure MTTF}

A level variable called $M T F(t)$ with a flow variable that enters into it and that is equal to $R(t)$ must be created as the Figure 3 show. Since MTTF is an improper integral, it is a limit value that can be approximated as $M T F(t)$ at the end of simulation.

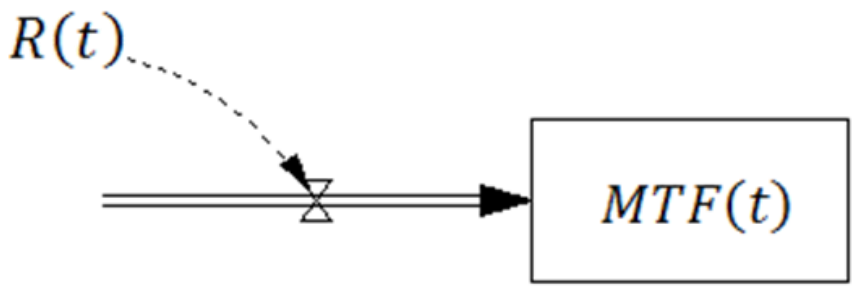

Fig 3. TD to calculate MTTF

Source: Authors.

The Figures 4-6 show the functions of the previous performance measures, and where $A=0.0165$ and $M T T F=1.315$ are estimated.

\section{CONCLUSIONS}

The main advantage of a EDSM for a CMTC that represents a RMSS is the possibility of finding numerical solution without the need to express explicitly system of ODEs. These solutions are calculated for a any time interval and it are not restricted to a particular instant or to steady-state probabilities when $(t \leftrightarrow \infty)$.

Further, the use of DS software allow to do calculations and analysis that are not easy with others approaches and tools. First, the times to failure or repair may follow different probability distributions such as Weibull or Log-logistic. And second, different types of measures can be estimated. Thereby, complex systems can be studied efficiently by means of nonhomogeneous MM.

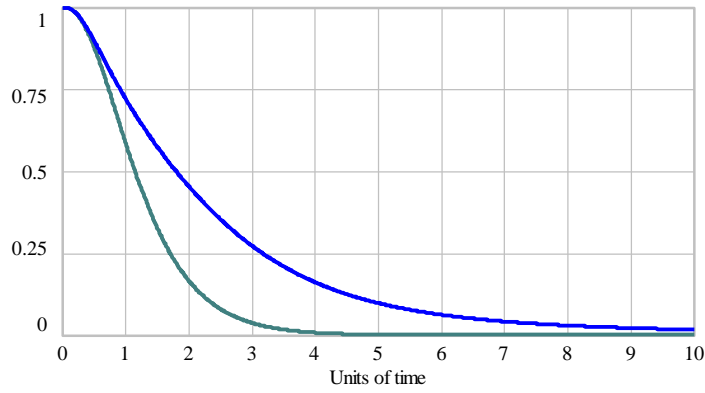

A(t)

Fig 4: Availability $A(t)$ and Reliability $R(t)$. Source: Authors.

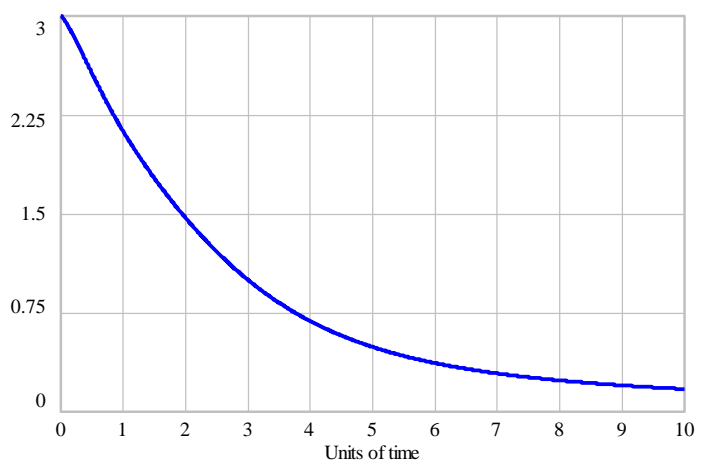

Fig 5: Expected performance.

Source: Authors.

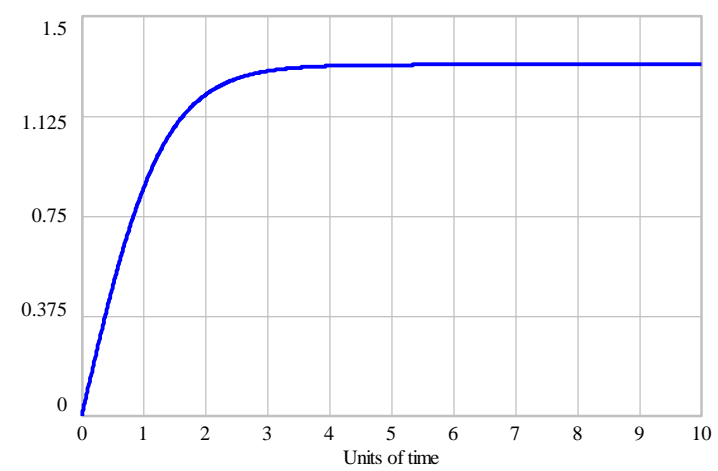

Fig 6: Mean Time To Failure MTTF.

Source: Authors.

However, a ESDM is based on the MM and therefore if RMSS does not satisfy the markovian assumptions any results 
will be incorrect. On the other hand, the system simplification is necessary, since ESDM can be complicated when there are many states and transitions. The system may be modeled without this simplification, but the analysis and calculations can be made simpler by grouping equivalent states in terms of some property.

As a result, future work in the reliability field don't should assume constant transition rates. If system has time-varying rates then a nonhomogeneous MM should be used and solved with an ESDM.

\section{REFERENCES}

[1] S. Distefano and A. Puliafito, "Dependability modeling and analysis in dynamic systems." 2007 IEEE International Parallel and Distributed Processing Symposium, IEE., pp. 1-8, 2007. DOI: 10.1109/IPDPS.2007.370601

[2] S. Distefano, "Reliability and dependability modeling and analysis of dynamic aspects in complex systems," 2009 Eighth IEEE International Conference on Dependable, Autonomic and Secure Computing, IEE., pp. $43-48,2009$. DOI: 10.1109/DASC.2009.145

[3] A. N. Ajah et al, "Hierarchical markov reliability/availability models for energy \& industrial infrastructure systems conceptual design," Computer aided chemical engineering., vol. 21, pp. 1753 1758, 2006. DOI: 10.1016/S1570-7946(06)80301-9

[4] P. Pukite and J. Pukite, "Markov modeling for reliability analysis," Wiley-IEEE Press, 1998

[5] W. Kuo and M. J. Zuo, "Optimal reliability modeling: principles and applications," John Wiley \& Sons, 2003.

[6] K. B. Misra, "Maintenance engineering and maintainability: An introduction," Handbook of performability engineering, Springer, London, pp. 755-772, 2008. DOI: 10.1007/978-1-84800-131-2_46

[7] G. Leviti and A. lisnianski, "A new approach to solving problems of multi-state system reliability optimization," Quality and reliability engineering international., vol. 17, no. 2, pp. 93-104, 2001. DOI: $10.1002 /$ qre. 388

[8] M. Xie, Y. S. Dai and K. L. Poh, "Computing system reliability: models and analysis", Springer Science \& Business Media., 2004.

[9] [9] I. W. Soro, M. Nourelfath and D. Ait-Kadi. "Performance evaluation of multi-state degraded systems with minimal repairs and imperfect preventive maintenance," Reliability Engineering \& System Safety., vol. 95, no. 2, pp. 65-69, 2010. DOI: 10.1016/j.ress.2009.08.004

[10] Y. W. Liu and K. C. Kapur, "New models and measures for reliability of multi-state systems," Handbook of performability engineering, Springer, London, pp. 431-445, 2008. DOI:10.1007/978-1-84800-131-2_28

[11] A. Lisnianski, I. Frenkel and Y. Ding, "Multi-state system reliability analysis and optimization for engineers and industrial managers", Springer Science \& Business Media., 2010. DOI:10.1007/978-1-84996-320-6

[12] J.L Wang, "Markov-chain based reliability analysis for distributed systems," Computers \& Electrical Engineering., vol. 30, no. 3, pp. 183-205, 2004. DOI: 10.1016/j.compeleceng.2002.02.001

[13] Y. A. Ermolin, "Reliability calculation under seasonally varying failure rate," ISA transactions., vol. 46, no. 1, pp. 127-130, 2007. DOI: 10.1016/j.isatra.2006.06.005

[14] S. M. Ross, "Introduction to Probability Models," California: Elsevier Inc., 2007.

[15] H. C. Tijms, "A first course in stochastic models," John Wiley and sons., 2003. DOI:10.1002/047001363X

[16] M. Rausand and A. Hoyland, "Sytem Reliability Methods and Applications," Jhon Wiley \& Sons., 2004. DOI:10.1007/978-085729-688-7

[17] J. V. Bukowski, "Using Markov models to compute probability of failed dangerous when repair times are not exponentially distributed," RAMS'06. Annual Reliability and Maintainability Symposium, IEEE, pp. 273-277, 2006. DOI: 10.1109/RAMS.2006.1677386.
[18] T. Rolski, H. Schmidli, V. Schmidt and J. L. Teugels, "Stochastic processes for insurance and finance," John Wiley \& Sons., 1999. DOI: $10.1002 / 9780470317044$

[19] M. Arns, P. Buchholz and A. Panchenko, "On the numerical analysis of inhomogeneous continuous-time Markov chains," INFORMS Journal on Computing., vol. 22, no. 3, pp. 416-432, 2010. DOI: 10.1287/ijoc.1090.0357

[20] W. J. Stewart, "Probability, Markov chains, queues, and simulation: the mathematical basis of performance modeling," Princeton university press., 2009. DOI: $10.2307 / j$.ctvem4gtc

[21] E. S. e Silva and H. R. Gail, "Transient solutions for Markov chains," Computational probability. Springer, Boston, MA, pp. 4379, 2000. DOI: 10.1007/978-1-4757-4828-4_3

[22] D. G. Zill, "Differential equations with applications in modeling," México, D.F: Thomson Editores, S.A., 2006.

[23] J. B. Fonollosa, J. M. Sallán and A. Suñé, "Quantitative methods of industrial organization," Barcelona: Ediciones de la Universidad Politécnica de Catalunya., 2002.

[24] B. S. Dhillon, "Reliability, quality, and safety for engineers," CRC Press, 2004. DOI:10.1002/qre.754

[25] X. Bao and L. Cui, "An analysis of availability for series Markov repairable system with neglected or delayed failures," Ieee Transactions on reliability., vol. 59, no. 4, pp. 734-743, 2010. DOI: 10.1109/TR.2010.2055915.

[26] A. Platis, N. Limnios and M. Le Du, "Dependability analysis of systems modeled by non-homogeneous Markov chains," Reliability Engineering \& System Safety., vol. 61, no. 3, pp. 235-249, 1998. DOI:10.1016/S0951-8320(97)00073-2

[27] Y. Liu and H. Z. Huang, "Optimal replacement policy for multistate system under imperfect maintenance," IEEE Transactions on Reliability., vol. 59, no. 3, pp. 483-495, 2010. DOI: 10.1109/TR.2010.2051242.

[28] Y. Liu and K. K. C. Kapur, "Customer's cumulative experience measures for reliability of non-repairable aging multi-state systems," Quality Technology \& Quantitative Management., vol. 4, no. 2, pp. 225-234, 2007. DOI: 10.1080/16843703.2007.11673147

[29] A. Lisnianski, I. Frenkel, L. Khvatskin and Y. Ding, "Maintenance contract assessment for aging systems," Quality and Reliability Engineering International., vol. 24, no. 5, pp. 519-531, 2008. DOI: $10.1002 /$ qre. 913

[30] D. C. Lane, "Should system dynamics be described as a 'hard'or "deterministic'systems approach," Systems Research and Behavioral Science: The Official Journal of the International Federation for Systems Research., vol. 17, no. 1, pp. 3-22, 2000. DOI:10.1002/(SICI)1099-1743(200001/02)17:1<3::AIDSRES344>3.0.CO;2-7

[31] M. Narváez and J. C. Osorio, "Methodology for the modeling of Nonhomogeneous Continuous-Time Markov Chains, using Systems Dynamics," IX Latin American Congress of System Dynamics., 2011.

[32] J. Sterman, "Business dynamics: systems thinking and modeling for a complex world," Irwin McGrawHill, 2000.

[33] J. R. Burns, "Simplified translation of CLDs into SFDs," proceedings of the International Conference of the System Dynamics Society., pp. 1-28, 2001.

[34] A. L. Pugh, "Simulation software and numerical issues," Knowledge for Sustainable Development, An Insight into the Encyclopedia of Life Support Systems. Oxford: UNESCO Publishing - Eolss Publishers, 2009.

[35] Ventana systems Inc. (2002). Vensim ${ }^{\circledR}$ DSS, Professional, Standard, PLE Plus, PLE with Causal Tracing $®$, Reality Check $®$ y SyntheSimTM. User Guide. Version 5. 1988-2002. 


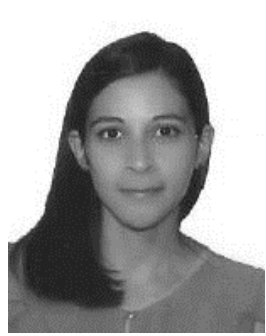

M. Narváez-Velasco, nacida el 23 de diciembre en Cali, Colombia. Ingeniera Industrial egresada de la Universidad del Valle, Santiago de Cali, Colombia, en 2012. Magister en Finanzas de la Universidad Icesi, Santiago de Cali Colombia, en 2018.

Entre los años 2012-2016, desempeñó cargos de coordinación en procesos de compras y abastecimiento de las empresas Compañía Internacional de Alimentos S.A.S y Fleischmann Foods SA. Actualmente es consultora funcional de finanzas en proyectos de implementación y soporte de aplicaciones Oracle en Iteria SAS.

ORCID: https://orcid.org/0000-0001-7461-2139

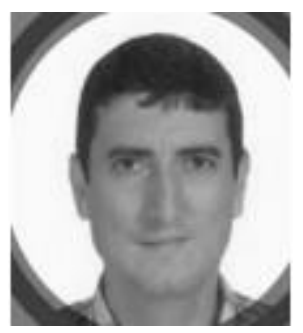

J.C. Osorio-Gómez, nacido el 20 de septiembre de 1975 en Buga, Valle del Cauca, Colombia. Ingeniero Industrial, Especialista en Logística, Magister en Ingeniería Industrial, Doctor en Ingeniería Industrial de la Universidad del Valle, Santiago de Cali, Valle del Cauca, Colombia. Actualmente Profesor titular de la Escuela de Ingeniería Industrial de la Universidad del Valle.

ORCID: http://orcid.org/0000-0001-5625-5609 